\section{RMD Open}

Rheumatic \&

Musculoskeletal Diseases

\title{
The arthritis connection to inflammatory bowel disease (IBD): why has it taken so long to understand it?
}

\author{
Maedeh Ashrafi, ${ }^{1}$ Kristine A Kuhn, ${ }^{2}$ Michael H Weisman (1) ${ }^{3}$
}

To cite: Ashrafi M, Kuhn KA, Weisman $\mathrm{MH}$. The arthritis connection to inflammatory bowel disease (IBD): why has it taken so long to understand it? RMD Open 2021;7:e001558. doi:10.1136/ rmdopen-2020-001558

Received 23 December 2020 Revised 16 March 2021 Accepted 18 March 2021
Check for updates

(c) Author(s) (or their employer(s)) 2021. Re-use permitted under CC BY-NC. No commercial re-use. See rights and permissions. Published by BMJ.

${ }^{1}$ Medicine, Shahid Beheshti University of Medical Sciences, Tehran, Iran (the Islamic Republic of)

${ }^{2}$ Internal Medicine, University of Colorado - Anschutz Medical Campus, Aurora, Colorado, USA Internal Medicine, Stanford University School of Medicine, Stanford, California, USA

Correspondence to Professor Michael H Weisman; weisman@cshs.org

\section{ABSTRACT}

Inflammatory bowel disease (IBD) associated arthritis is a subgroup of spondyloarthritis (SpA) that has suffered from lack of recognition in rheumatology clinical and research circles for over 100 years. Although clinically distinguishable from rheumatoid arthritis and ankylosing spondylitis, it took advances in detection systems in the middle of the last century (rheumatoid factor, HLA-B27) to convincingly make the final separations. We now know that significant numbers of patients with SpA have associated clinical IBD and almost half of them show subclinical gut inflammation, yet the connection between the gut and the musculoskeletal system has remained a vexing problem. Two publications from Nathan Zvaifler (one in 1960, the other in 1975) presciently described the relationship between the gut and the spine/peripheral joints heralding much of the work present today in laboratories around the world trying to examine basic mechanisms for the connections (there are likely to be many) between the gut, the environment (presumably our intestinal flora) and the downstream effect on the musculoskeletal system. The role of dysregulated microbiome along with microbiomedriven Thelper 17 cell expansion and immune cell migration to the joints has been recognised, all of which occur in the appropriate context of genetic background inside and outside of the human leucocyte antigen system. Moreover, different adhesion molecules that mediate immune cells homing to the gut and joints have been noted. In this review, we studied the origins and evolution of IBD-arthritis, proposed pathogenic mechanisms and the current gaps that need to be filled for a complete understanding of IBD-arthritis.

\section{INTRODUCTION}

The initial description of a potential cause and effect relationship between arthritis and inflammatory bowel disease (IBD) likely goes back to well over 100 years ago in 1895 where William H White wrote, 'among twenty-three cases of ulcerative colitis... two had urate of soda in their joints'. ${ }^{1}$ Almost 30 years later and into the next century, in 1922, Rea Smith, a surgeon based in Los Angeles, noted alleviation of swelling, pain and joint immobility in multiple patients with chronic arthritis on the conclusion of various bowel operations.

\section{Key messages}

After a very long hiatus characterised by our inability to reconcile confusing and often contradictory clinical studies, it was not until recent scientific discoveries of rheumatoid factor and HLA-B27 separated RA from SpA that we were able to be convinced a unique form of arthritis occurred with IBD in much greater frequency than by chance alone.

- We now know that significant numbers of patients with SpA have associated clinical IBD as well as subclinical gut inflammation, yet the connection between the gut and the musculoskeletal system has remained a vexing problem.

- In this review we discuss research advances into the aetiopathogenesis of IBD regarding the intestinal mucosa and immunity at the gut level that provide the entry point for a putative environmental trigger of arthritis in patients with IBD.

- We suggest that attempts to close research gaps will require a rigorous and standardised approach to gathering patient populations with sound epidemiological tools in addition to the challenge of obtaining direct access, with advanced immunological techniques, to relevant human tissues such as intestine and enthesis structures.

Although he made mention of 'ileocaecal coil' changes on some of his patient's X-rays, it is difficult to tell if his patients had true IBD or another intestinal affliction; the full characterisation of the various features of IBD phenotypes were not generally appreciated throughout the USA at that time. He then stated, quite prophetically, that 'no study of a case of arthritis is complete without a careful investigation of the gastro-intestinal tract'.

A decade later at the Mayo Clinic, where quite a few patients with ulcerative colitis (UC) had assembled for patient care, Arnold Bargen in 1929 and Philip Hench in 1935, in separate publications, drew the attention to peripheral arthritis manifestations in their patients with UC. ${ }^{34}$ They had observed and studied 1500 patients with chronic UC; 60 had 
arthritis which they felt was the most common complication of the colitis except for polyposis. They went further in their review and expanded the descriptions which became the beginning of an appreciation of the heterogeneric nature of arthritis in IBD. Bargen and Hench described four types of arthritis: (1) Arthritis preceding UC for a fairly long time, resembling the atrophic variety ('atrophic arthritis' was the prior description of rheumatoid arthritis (RA)), and considered unrelated to colitis, (2) Atrophic arthritis and colitis occurring at the same time but progressing independently, (3) Arthritis resembling atrophic arthritis that occurs during colitis remission and not during exacerbation of the bowel disease, and (4) The more common type, a subacute arthritis that flares with colitis exacerbations and experiences relief with colitis remission; all of this latter type showing a striking conformity with remissions and exacerbations of both occurring simultaneously. They considered the first three types as the unrelated coincident associations between RA and IBD, and these investigators concluded the fourth and more common type was a specific complication of the colitis itself rather than a coincident association of another disease.

The rheumatism reviews published in 1936 commented that the foregoing data from Bargen and Hench were admittedly incomplete to establish a new condition, referring to a specific colitis-arthritis entity. ${ }^{5}$ However, the review authors did comment about certain points that did distinguish this entity from garden variety atrophic arthritis (which was clearly progressive and relentless) and these included facts that the clinical relationships among the appearance, activity and recovery from the colitis and arthritis were similar, and most importantly, there was a greater tendency to periodicity as well as to complete remissions in the arthritis compared with what is typically seen in usual atrophic (rheumatoid) arthritis.

The rheumatism reviews' authors clearly were wrestling with this newly recognised association between the gut and the joints. They were sceptical of those colleagues who were 'glibly incriminating more or less symptomless intestines as the cause of atrophic arthritis'. They stated that "Those who blame the bowels may find some comfort in the evidence which shows that arthritis and intestinal diseases can be causally related by the hematogenous route, but the rarity of a proved relationship should give one pause". The authors of the reviews stated quite specifically (and possibly presciently in the editorial comments section of the reviews) that there is a need for complete open-mindedness on this difficult problem of a symptomless gastrointestinal infection playing a role either as a primary or an underlying predisposing cause of arthritis. ${ }^{5}$

In retrospect, it is highly likely that the type of arthritis of large joints that occurs during colitis remission and not during exacerbation (Hench and Bargen type 3) reflects the now known association between colitis and the peripheral arthritis of ankylosing spondylitis (AS). This issue is examined in detail below; however, since AS was not recognised by Hench and Bauer (and particularly, by Bauer) as a separate entity from RA, it is very likely that it was assumed to be just another part of RA that, on occasion, was called rheumatoid spondylitis. ${ }^{6}$

There is a distinct literature gap from the late 1930s until the 1950 s for arthritis-IBD associations. Why did this happen?

We are unable to find IBD-arthritis descriptions in the literature for the next decade or during the World War II postwar years; neither was a connection mentioned or referenced in the standard nomenclature of diseases approved by the American Rheumatism Association of 1952. For example, the first two editions in 1950 and in 1954 of the textbook Harrison's Principles of Internal Medicine did not contain text, reference or discussion of IBD-related arthritis. ${ }^{6}$ Investigators who observed and commented on this information gap later in the century opined that the gap could be in part due to the attribution of these disease manifestations to be simply the coincidence of an association with RA. ${ }^{78}$

However, an alternate view of this literature gap is possibly related to a distraction caused by the description of a newly recognised arthritis syndrome potentially triggered by an exogenous infectious agent. The tenth rheumatism review published in 1953 describes a recently characterised condition called Reiter's Syndrome where the statement is made that 'Numerous reports on this syndrome had appeared' referring to the American and English literature reports from the preceding years. ${ }^{9}$ The very first actual description of Reiter's syndrome was made by the English physician Benjamin Brodie over a century earlier in 1818 where he observed a 45 -year-old man with arthritis, urethritis and conjunctivitis. ${ }^{10}$ In 1916, Reiter in Germany and Fiessinger-Leroy in France described postdysenteric cases of urethritis-arthritisconjunctivitis combinations occurring in soldiers living in close quarters during World War I. ${ }^{11}$ The initial characterisation of the syndrome in USA was performed by Walter Bauer and Ephraim Engleman in 1942, describing the Reiter's triad in a 23-year-old man with no history of preceding diarrhoea or venereal disease; these investigators acknowledged 'until the aetiology is established, this symptom complex should be referred to as a syndrome rather than a disease'. ${ }^{12}$

More comprehensive descriptions of this form of acute and subsequent chronic arthritis related to an infectious agent did occur during the intervening World War II years primarily from descriptions by Paronen $e t a l$ in Finland where prevalent close-quarters living conditions promoted the spread of bacillary dysentery across populations of civilians. ${ }^{13}$ American publications describing this condition also could have contributed to distracting investigators from further studies characterising IBDarthritis, although it was prophetically stated in the tenth rheumatism review that postdysenteric arthritis can be clinically indistinguishable from Reiter's syndrome. ${ }^{9}$ Further, it is clearly mentioned in this 1953 rheumatism review that a possible relationship to bacillary dysentery 
should be considered under the discussion of the section called Aetiology of Reiter's Syndrome.

Bringing the gut-arthritis connection to the forefront of critical thinking was a result of an unintentional experiment of nature, again related to the war effort. A shipboard epidemic of bacillary dysentery took place immediately after an American naval vessel left port from somewhere in Europe in 1962, where Dr Rolf Noer carefully documented the clinical sequelae of this epidemic from the beginning to its conclusion. He found 9 cases of Reiter's syndrome out of 602 cases of bacillary dysentery, findings which could not be explained by chance. He then stated, "It appeared that our cases of Reiter's disease were sequelae of bacillary dysentery". ${ }^{14}$ Later and well after the genetic association between HLA-B27 and spondyloarthritis (SpA) was discovered, Calin and Fries were able to locate, examine, and clinically and genetically characterise five of the original nine Noer cases; they discovered an $80 \%$ positivity rate for HLA-B27 in these former navy enlisted men, all of whom had subsequently experienced severe, progressive destructive SpA. Calin and Fries concluded that B27 had an effect on both the incidence and severity of postdysenteric Reiter's syndrome. $^{15}$

Ahvonen et al in 1969 studied various arthritis manifestations associated with Yersinia enterocolitica infection and wrote, 'transient non-purulent (reactive) arthritis with acute onset has been occasionally reported in association with bacterial infections such as those caused by Brucella, Shigella, and Salmonella typhimurium'. They introduced the term 'reactive arthritis' for the first time in rheumatology literature. ${ }^{16}$ A clear and convincing separation between RA and what appeared to be an infectious agent (either from the gut or the genitourinary tract) triggering an acute and then a chronic disease most assuredly required the widespread recognition of the clinical and research importance of what later tuned out to be rheumatoid factor. ${ }^{17} 18$ The discovery and characterisation of the antibody nature ${ }^{19}$ of rheumatoid factor (and its absence in the patients with IBD-arthritis) is likely to be a major reason for the subsequent rejuvenated and focused interest in IBD-arthritis ${ }^{20}$ as a separate and distinguishable entity.

\section{When was RA finally separated from the arthritis of IBD?}

Luis Fernandez-Herlihy, an influential practitioner from the Lahey Clinic in Boston, summarised in 1959 his opinion describing (from a database of over 500 cases) the range of articular manifestations in patients with UC. He employed the following five categories: rheumatoid spondylitis, RA, erythema nodosum, arthralgias and acute toxic arthritis. Among these, acute toxic arthritis had the closest relationship with colitis; he noted that this category became clinically evident only with the exacerbation of colitis and relieved on colitis remission without any residual deformity. He then postulated 'it is possible that acute toxic arthritis constitutes a milder, earlier, or perhaps an atypical form of Rheumatoid Arthritis'. ${ }^{21}$
However, clarity from Verna Wright and Geoffrey Watkinson whose observations were published in the same year as Fernandez-Herlihy nevertheless made a point of distinguishing 'colitic arthritis' from RA; this was based on the negative results from the (newly recognised) agglutination test for RA, and the recognition of asymmetrical joint involvement, lack of joint deformity and the absence of rheumatoid nodules in those with colitic arthritis. ${ }^{22}$ At around the same time, rheumatologists along with gastroenterologists began emphasising the presence of axial involvement in patients with IBD. Steinberg and Storey in 1957 made what appears to be the first association between AS and Crohn's disease.$^{23}$ Eric Bywaters and Barbara Ansell in the following year (1958) reported a case series of 37 patients with UC and arthritis, 6 of whom had sacroiliitis. They distinguished these patients from typical AS without colitis, from reactive arthritis (known at the time as Reiter's syndrome), and from RA in three ways based on more female patients in the colitis group, absence of urethritis, and negative agglutination tests, respectively. ${ }^{7}$ The first US scholarly and scientifically controlled observation revealing a relationship between UC and AS was performed by Zvaifler and Martel in 1960; 100 cases of UC were chosen at random from a coded Roentgen database for UC. These investigators observed a $6 \%$ prevalence of AS when these imaging studies were reread. ${ }^{24}$ They stated that the concurrence of spondylitis with UC was too frequent to be explained by chance.

\section{How was IBD-associated arthritis eventually separated (or not) from AS?}

The debate on the relationships among IBD-associated arthritis, RA and AS continued into the 1960s. While some believed that sacroiliitis seen in patients with IBD is simply the coincident association of the AS with IBD, ${ }^{25-27}$ others concluded that this is a specific arthritis similar to, yet distinct from, AS. ${ }^{88}$ McEwen et al in 1962 studied 87 patients with IBD with arthritis manifestations and hypothesised four types of relationships among IBD-arthritis, RA and AS: (1) If RA and AS are the same diseases, then spondylitis and peripheral arthritis are the RA occurring in patients with UC, (2) If RA and AS are distinct diseases, then peripheral arthritis is RA and spondylitis is AS, (3) The peripheral arthritis in UC is distinct from RA, but the spondylitis is AS, and (4) Both peripheral arthritis and spondylitis are specific to UC, distinct from RA and AS. ${ }^{29}$ These statements made by McEwen in his influential paper, in retrospect, do not particularly shed much light on the subject, and are confusing at best.

Finally, Wright and Moll in their critical and influential paper of 1974 concluded: 'the features of the sacroiliitis accompanying psoriasis, ulcerative colitis, and Crohn's disease are, in our view, also indistinguishable from those seen in uncomplicated ankylosing spondylitis'. They further suggested quite a strong association to occur among all of the conditions known as SpA today. ${ }^{30}$ It was the landmark discovery of the genetic association between HLA-B27 and AS, published in $1973,{ }^{31}$ that provided 
evidence for a unifying concept of SpA. This important clinical observation as well as the long-recognised occurrence of patients with SpA and patients with IBD in the same family brought major attention towards the genetic component as a unifying concept. Brewerton stated in 1974 that ' $6 \%$ of patients with UC have AS. The reason for this association is uncertain. Genetic factors in both diseases may be related. HLA antigen now adds a new dimension to this argument, carrying the high frequency of HLA-B27 into the common ground between the two diseases' ${ }^{32}$

\section{What theories are proposed to explain the pathogenesis of IBD-associated arthritis?}

Multiple theories have been promulgated to account for the underlying pathogenesis of IBD-arthritis. Ernest Fletcher in 1951 noted the long hospitalisation periods taking place in patients with UC and hypothesised the probable cause of arthritis as follows: 'it is uncertain whether this complication is due to the long confinement to bed or the main disease' ${ }^{33}$ Steinberg and Storey proposed the spread of a toxic agent through the intestinal wall to the pelvic veins and then subsequently to the vertebral veins. These veins, called Batson's plexus, were initially suggested as having the capacity to permit the spread of metastasis from pelvic tumours, particularly the prostate, through the veins to the spine. A similar and parallel explanation for the development of spinal disease to result from infections in the various organs from the pelvis was described by Romanus studying the genitourinary tract association with spondylitis ${ }^{23} 34$ and later put forth as a possible explanation for the spread of an infection in the colon to the spine. The latter theory was questioned by Zvaifler and Martel in 1960 when they observed that the spondylitis antedated the colitis by many years in a number of their patients. ${ }^{24}$

\section{Why is 1975 a landmark year for our understanding of IBD- associated arthritis?}

In an extraordinarily prescient paper published in 1975, Zvaifler reviewed theories of IBD-arthritis pathogenesis in detail based on the then existing modern views of immune-mediated events in rheumatic diseases. He summarised its pathogenesis as likely existing within the following possibilities:

1. If UC was caused by an exogenous agent, such as a microbe or virus, then the arthritis would result from dissemination of an infectious agent to the joint. This would occur whether as a primary event with involvement of both intestine and joints at the same time, or the articular tissues could be invaded by an organism which had gained access to the body through inflamed gut mucosa. However, Zvaifler was concerned that the episodic non-destructive nature of the joint disease in colitis would be unusual for a chronic infection. He notes, however, that in animal models of infectious agent arthritis the process can be chronic and progressively destructive long after the organism can be isolated from the joint.

2. Another attractive hypothesis is that both the bowel and articular disease are mediated by a 'hypersensitivity' mechanism. In this case, both the bowel and joint diseases are caused by cellular or immune mechanisms elaborated by a common antigen shared by both the bowel and the joint. This common antigen could be altered in some way, either by the invading organism itself or an as yet unknown mechanism involving the loss of self-tolerance. Zvaifler likens this mechanism to what had been proposed by others for the explanation of why cardiac and articular inflammation occurs in patients with rheumatic fever.

3. Zvaifler's third explanation involves the joint as an 'innocent bystander' that is injured by the deposition of circulating immune complexes such as been postulated for the arthritis of SLE or the joint disease that accompanies infectious hepatitis B-related arthritis. However, he felt that this explanation was unlikely because other signs of circulating immune-complex deposition were absent (ie, depressed complement products, immunofluorescent markers in tissues, etc). He states that our understanding of the arthritis of IBD awaits a better understanding of the pathogenesis of IBD itself. ${ }^{20}$

Is there new evidence providing a greater understanding of the cause of IBD-related arthritis beyond any one of Zvaifler's proposed three mechanisms from 1975 ?

Is the intestinal mucosa the entry point for the environmental trigger of the arthritis in IBD?

Recent investigations have shown that microbial alteration or dysbiosis has been noted in patients with SpA. Despite a number of studies describing changes in the relative abundance of multiple bacterial taxa in patients with $\mathrm{SpA}$ relative to controls, ${ }^{35}$ a singular taxon does not emerge as linking to SpA. It is important to note that the role of gut microbiota in SpA pathogenesis was earlier established in animal models going back almost 30 years. HLA-B27/human $\beta 2 \mathrm{~m}$ transgenic rats spontaneously develop intestinal inflammation and arthritis which is clinically comparable to HLA-B27-associated disorders in humans. ${ }^{36}$ In 1994 Taurog et al studied 37 HLA-B27 transgenic rats under germ-free (GF) conditions for 23-60 weeks. None of these rats developed intestinal or joint inflammation. They concluded that gut microbial flora plays an important role in the gut and subsequently triggers joint inflammation. ${ }^{37}$ Capitalising on these earlier observations, scientists using sophisticated immunological tools also studied the relationship between gut flora, host immunogenotype and SpA development.

Multiple studies in HLA-B27 transgenic rats and humans have shown the direct impact of HLA-B27 on gut dysbiosis. ${ }^{38-40}$ In individuals without AS, those with HLA-B27 shared dysbiotic features with what has been reported for AS and unlike HLA-B27-negative individuals, suggesting that the presence of HLA-B27 could drive 
gut dysbiosis relevant to disease. ${ }^{40}$ As a demonstration of the linkage between HLA-B27-related dysbiosis and pathology, HLA-B27 transgenic rat strains within varying environments demonstrated different gut microbiota; ${ }^{41}$ however, two of the strains developed intestinal inflammation and T helper cells (Th17)-related immunity that correlated with specific microbiota. This implies that the HLA-B27 effect on dysbiosis is highly dependent on the host genetic background and/or environment pointing to the 'ecological model dysbiosis'. ${ }^{42}$

Ranjeny Thomas et al demonstrated an interleukin (IL) 23-dependent SpA phenotype in ZAP-70 mutant (SKG) mice after administration of curdlan (a purified beta1,3-glucan which triggers inflammation). ${ }^{43}$ Following this observation in additional studies, they investigated the SpA development in SKG mice under GF or specific pathogen-free (SPF) conditions. These investigators realised that unlike arthritis, ileitis development was dependent on the microbiota; ileitis occurred in SPF SKG mice while it was absent in GF SKG mice. Arthritis occurred in both GF and SPF SKG mice, while the severity was more pronounced in SPF SKG mice. ${ }^{44}$

Finally, Schaubeck et al studied the impact of bacterial communities in ileitis development in $\mathrm{TNF}^{\mathrm{ARE} /+}$ mice. $\mathrm{TNF}^{\Delta \mathrm{ARE} /+}$ mice carry a deletion in the tumour necrosis factor adenosine-uracil elements resulting in TNF mRNA stabilisation and TNF-driven spontaneous ileitis and arthritis development. GF TNF ${ }^{\Delta \mathrm{ARE} /+}$ mice were protected from ileitis and develop intestinal inflammation only when colonised with caecal bacterial communities from inflamed SPF TNF ${ }^{\triangle A R E /+}$ mice. These GF $\mathrm{TNF}^{\triangle \mathrm{ARE} /+}$ did not develop ileitis on colonisation with the Crohn's disease pathobiont Escherichia coli LF82 pointing to the community effect of microbes and dysbiosis in pathology rather than specific single pathobionts. ${ }^{45}$ More recent work in $\mathrm{TNF}^{\mathrm{AARE} /+}$ mice revealed that both ileitis and arthritis were dependent on gut microbiota since mice treated with broad-spectrum antibiotics had significantly less inflammation in these areas. ${ }^{46}$ However, in humans, the relationship between gut microbes and the development of arthritis, whether causal or epiphenomenal, remains less clear and will require much more investigation to establish mechanistic connection(s).

Is there a pathway for a primary immune-related mechanism for bowel disease to trigger arthritis in genetically susceptible individuals?

The exact mechanism of how the microbiome leads to SpA pathology either in the axial or peripheral skeleton, is yet to be elucidated. Many mechanisms by which intestinal microbiota can influence the development of arthritis have been proposed and are reviewed elsewhere ${ }^{47}$ An overall theme relevant to IBD and SpA relies on strong evidence for commensal bacteria driving the local accumulation of Th17. ${ }^{49}$ Transfer of adoptive $\mathrm{CD} 4+\mathrm{T}$ cells into SPF or GF $\mathrm{RAG}^{-/}$mice results in an accumulation of Th17 cells in colonic lamina propria and colitis development in SPF mice but not in GF mice,$^{50}$ thus demonstrating the important connection between microbiota, Th17 cells and IBD. In relation to SpA, Th17 cells are found in peripheral blood and synovial fluid of patients with $\mathrm{SpA}$ and positively correlate with joint and systemic inflammation markers. ${ }^{51}$ IL-23 leads to the production of IL-17, IL-22 and to a lesser extent of TNF by Th17 cells. ${ }^{52}$ IL-17 has proinflammatory effects on different cell types including fibroblasts, osteoblasts, monocyte/macrophages and epithelial cells, as well as recruiting and activating neutrophils. ${ }^{53}$ It is therefore postulated that the IL23/17 axis plays an important role in the pathogenesis of both SpA and IBD.$^{54}$ Other potential IL-17 producing cells include $\gamma \delta \mathrm{T}$ cells, innate lymphoid cells (ILCs) and mucosa-associated invariant T cells (MAITs) ${ }^{55}$ These cells with characteristics of innate immune cells are found at mucosal tissues and can show a regulatory/immunoprotective or proinflammatory role by secreting IL-17 in response to different microbes. ${ }^{56}$ The role for unconventional $\mathrm{T}$ cells in the SpA pathogenesis initially was demonstrated in a murine model by Sherlock $e t$ al. They found that a subset of entheseal resident $\mathrm{T}$ cells (most likely $\gamma \delta \mathrm{T}$ cells) can induce SpA in mice independent of Th17 on induced IL-23 overexpression (using minicircle DNA technology). ${ }^{57} 58$ Additional studies have shown the expansion of ILC3s, $\gamma \delta \mathrm{T}$ cells and MAIT cells within the intestinal tissue, circulation and/or synovial fluid of patients with SpA..$^{58-60}$

IL-17 also plays an important role in salmonellainduced reactive arthritis. In an animal model of salmonella enterocolitis, the joint lesion appears early in the course of the disease and the IL-17 expression of the gut and mesenteric lymph nodes resemble that of popliteal and inguinal lymph nodes ${ }^{61} \gamma \delta \mathrm{T}$ cells contribute to IL-17 production in early salmonella enteritis. ${ }^{62}$ In a salmonellainfected mouse model study, inhibiting $\gamma \delta \mathrm{T}$ cells significantly reduced the IL-17 expression in mesenteric lymph nodes and abrogated the inflammatory response in the gut and joints, thus further suggesting the important role for $\gamma \delta \mathrm{T}$ cells in salmonella-induced reactive arthritis. ${ }^{63}$

The role that HLA-B27 plays in the molecular pathogenesis of $\mathrm{SpA}$ is most certainly in need of clarification if we are to understand the relationship between the gut and the joint. Clinical observations have shown that a variable but high range $(80 \%-95 \%)$ of patients with AS are HLA-B27-positive; nevertheless a much wider and more variable range $(25 \%-78 \%)$ of patients with AS associated with IBD are HLA-B27-positive ${ }^{64-66}$ likely reflecting different sources of patient collections. Multiple theories have been proposed on how HLA-B27 might contribute to the SpA. Misfolding theory links HLA-B27 to the IL-23/17 axis. The misfolding theory for the role of HLA- B27 consists of the primary observation that the HLA-B27 heavy chain folding process is slow, leading to misfolding with the misfolding chains accumulating in the endoplasmic reticulum (ER), leading to ER stress and unfolded protein activation (UPR). Further, activation of the UPR response leads to increased IL-23 production with subsequent Th17 expansion in response to pattern 
recognition receptors agonists (LPS). ${ }^{6768}$ The molecular mimicry theory involves a possible homology between an HLA-B27 sequence and an antigen derived from a virus or enterobacteria ${ }^{69}$ while another theory suggests that macrophages expressing HLA-B27 will present specific bacterial antigens that activate CD4+ T cells causing them to migrate to the joint. ${ }^{70}$

IBD and AS also share other genetic factors residing outside the MHC region. Single nucleotide polymorphisms within the IL-23 receptor locus which encodes a subunit of the receptor for IL-23, thus could play an important role in the pathogenesis of both diseases. ${ }^{71} 72$ Therefore, whether the process of microbiome development of mucosal immunity or HLA-B27 itself, the primary connection between the gut and the joint seems to lie along the Th17 pathway.

What is known or proposed for the aetiopathogenesis of IBD that permits arthritis to occur in these patients?

There is an increased risk for clinical IBD in patients with axSpA (estimated to be around 10\%) and nearly half of patients with SpA have subclinical gut inflammation depending on the detection system employed. ${ }^{73}{ }^{74}$ Intestinal barrier disruption in response to microbial dysbiosis can be associated with intestinal immune cell infiltration and later migration of these cells to the joints. A recent study in mice with collagen-induced arthritis demonstrated that treatments inhibiting intestinal barrier disruption can attenuate the arthritic symptoms in these mice and further link the gut to the joints. ${ }^{75}$ Homing of mucosal leucocytes to joints may play an important role in SpA pathogenesis. Salmi et al observed the binding of normal gut immune cells to synovial tissue for the first time in $1995 .^{76}$ In their subsequent studies, they concluded that gut-derived leucocytes display a variety of adhesion molecules in patients with IBD as opposed to what has been observed in normal healthy individuals. They also observed greater adhesion tendency directed to the synovial membrane for gut-derived leucocytes when compared with peripheral blood leucocytes in patients with IBD, pointing to the selectivity of synovial tissues for gut-originating cells. ${ }^{77}$

Tissue-specific homing is regulated by particular adhesion molecules and chemokine receptors; for the gut-associated lymphoid tissue, dendritic cells induce expression of $\alpha 4 \beta 7$ and CCR9 on T cells resulting in gut tropism and localisation in the small intestine. ${ }^{78} \mathrm{~T}$ cells activated in secondary lymphoid organs home to the gut mucosa through the interaction between $\alpha 4 \beta 7$ on T cells and MadCAM1 on endothelial cells as well as CCR9 (T cell)/CCL25 (intestinal endothelial cells) ${ }^{79}{ }^{80}$ Synovial tissues completely lack MadCAM-1, but the homing of gut-derived leucocytes can occur through other molecules. Memory-like T lymphocytes isolated from IBD gut use VAP-1, CD44, interaction between CD18 and ICAM-1, and $\alpha 4$ and VCAM-1 for synovial adhesion while immunoblasts from IBD gut mainly use VAP-1 for binding to synovial vessels. $^{77}$
In addition to lymphocytes, macrophages also avidly bind to synovial vessels. This adhesion occurs mainly through interactions with P-selectin glycoprotein ligand$1 /$ P-selectins. ${ }^{77}$ Macrophages play an important role in carrying mucosal antigens to synovium, triggering inflammation via gut-originated $T$ cells. In a study of two patients with reactive arthritis, clonal $\mathrm{T}$ cell reactivity to Yersinia was detected in synovial fluid. This reactivity was dependent on the presence of monocytes as antigen-presenting cells and HLA-DR. ${ }^{81}$ Macrophages expressing CD163, a member of scavenger receptor cysteine-rich superfamily producing proinflammatory cytokines, are expanded in the colonic mucosa of patients with Crohn's disease as well as in patients with SpA. These CD163 macrophages express high levels of HLA-DR. CD163 macrophages are also increased in the synovium of patients with SpA, further linking the gut to the joints. ${ }^{82} 83$

The aforementioned studies suggest gut-derived immune cells traffic between the two sites, but studies definitively showing this mechanism to take place consistently in human disease have not been done. However, a recent study in $\mathrm{TNF}^{\mathrm{ARE} /+}$ mice ${ }^{84}$ demonstrated an expansion of lymphocytes in the colon prior to the onset of colitis that normalise by the time they are expanded in inflamed joints. Additionally, using photolabelling, the authors establish mobilisation of $\mathrm{T}$ cells from gut to the joint. ${ }^{46}$ Such work verifies a direct connection between the gut and the joint, although studies addressing targeted mechanisms will need to amplify how specific gut microbiota and immunity tie to joint pathology.

\section{What are the challenges, proposed by Zvaifler, to fully} understand the mechanisms as to why IBD occurs in the first place?

In spite of significant progress over the past 25 years linking the gut to the joint, do we really know how immunity at the gut level affects the joint? Although bacterial products and immune cells with intestinal phenotypes can be identified in synovial fluid, the specific processes for translocation are not yet described. Are the bacterial products in the joint random or specific? We know from studies in bacteria-induced epidemics of reactive arthritis in humans that some bacterial products do remain in the joints once the intestinal infection has resolved, but it is difficult to understand the significance of this finding when we are talking about diseases with ill-defined origins and subsequent lifelong time periods of disease activity taking place with progressive damage along the way. What additional factors in the host or in the environment stimulate immune cells to traffic? How do the bacterial products or intestinally derived cells directly contribute to joint pathology? Additional research avenues can then interrogate such concepts of bacterial sampling and influences on mucosal immune responses as well as how host genetics like HLA-B27 and IL-23R polymorphisms affect such processes.

Genome-wide association studies have nicely revealed shared genetic risk loci between populations of IBD and 
AS such as the IL-23R among several others ${ }^{85} 86$ helping tie these two diseases together with a Th17-pathway pathophysiology. As mentioned previously, microbiome studies have begun to associate microbial dysbiosis in both IBD and AS with impairment of the gut barrier and immunopathology, usually Th17-related. Combining microbiome studies with metabolomics, altered tryptophan metabolism is observed in SpA, but not IBD, ${ }^{87}$ suggesting pathways where the two diseases diverge. Single-cell RNA sequencing and time-of-flight cytometry (CyTOF) can suggest additional pathogenic mechanisms for disease. For example, using CyTOF, Gracey et al identified an expansion of CD8+ T cells with gut-associated cell surface antigens integrin $\beta 7$ and CD103 in the synovial fluid of patients with $\mathrm{AS}^{89}$ which provides additional evidence of the gut-joint axis. However, by single-cell RNA sequencing of peripheral blood mononuclear cells Lefferts $e t$ al were able to identify a unique immunopathology of CD4+ cytotoxicityand interferon response in patients with both IBD and axial SpA, distinctive from either IBD or axial SpA alone. ${ }^{90}$ Thus, advances in such 'omics' technologies will continue to provide interesting and important connections between intestinal immune cells and disease (reviewed by Berlinberg and Kuhn ${ }^{91}$ ) and have the capacity to, and largely will, greatly accelerate these studies.

A significant need in this regard, and what poses an important limitation to our knowledge, is the challenge of obtaining direct access to relevant tissues such as the intestine and the enthesis structures. Use of newer in vitro systems like organ-on-a-chip and intestinal organoids derived from human subjects has the potential to allow mechanistic studies including microbe-host interactions ${ }^{92-95}$ without having to use murine models.

Finally, we conclude that attempts to move the field forward will also require a more rigorous and standardised approach to gathering patient populations with sound epidemiological tools. This will create a much-needed research collaboration between wellcharacterised clinical phenotypes and simultaneous molecular discoveries. Current efforts in the literature attempting to characterise IBD and AS populations are replete with inadequate phenotyping of highly heterogeneous groups of patients often from clinic-based cohorts containing small numbers of patients. Molecular mechanism discoveries must be linked and exposed to adequate and well-designed clinical studies; we await both. Nathan Zvaifler made a promise to us in 1975 that the pathogenesis of IBD must be understood before we can tackle the arthritis. Collaboration with our colleagues in the world of IBD would be a good start.

\section{Contributors All authors contributed equally to all aspects of the manuscript.}

Funding The authors have not declared a specific grant for this research from any funding agency in the public, commercial or not-for-profit sectors.

Competing interests None declared.

Patient consent for publication Not required.

Provenance and peer review Not commissioned; externally peer reviewed.
Data availability statement No additional data are available.

Open access This is an open access article distributed in accordance with the Creative Commons Attribution Non Commercial (CC BY-NC 4.0) license, which permits others to distribute, remix, adapt, build upon this work non-commercially, and license their derivative works on different terms, provided the original work is properly cited, appropriate credit is given, any changes made indicated, and the use is non-commercial. See: http://creativecommons.org/licenses/by-nc/4.0/.

ORCID iD

Michael H Weisman http://orcid.org/0000-0001-5568-388X

\section{REFERENCES}

1 Hale White W. Colitis. The Lancet 1895;145:537-8.

2 Smith R. Treatment of Rheumatoid arthritis by colectomy. Annals of Surgery 1922;76:515-78.

3 Bargen JA, Jackman RJ, Kerr JG. Complications and sequel of chronic ulcerative colitis. Annals of Internal Medicine 1929;3:335-52.

4 Hench PS. Acute and chronic arthritis. Nelson's Loose Leaf of Surgery, G H Whipple:1935104-75.

5 Hench PS, Bauer W, Fletcher AA, et al. The problem of rheumatism and arthritis; review of American and English literature for 1935: (third rheumatism review). Ann Intern Med 1936;10:783-4.

6 Ashrafi M, Ermann J, Weisman MH. Spondyloarthritis evolution: what is in your history? Curr Opin Rheumatol 2020;32:321-9.

7 Bywaters EG, Ansell BM. Arthritis associated with ulcerative colitis; a clinical and pathological study. Ann Rheum Dis 1958;17:169-83.

8 Bowen GE, Kirsner JB. The Arthritis of Ulcerative Colitis and Regional Enteritis ("Intestinal Arthritis"). Medical Clinics of North America 1965;49:17-32.

9 Robinson WD, Boland EW, Bunim JJ, et al. Rheumatism and arthritis: review of American and English literature of recent years. (tenth rheumatism review). I. Ann Intern Med 1953;39:498-618.

10 Travers R, Sayag-Boukris V. Sir Benjamin Collins Brodie (1783-1862) - a pioneer rheumatologist. Int J Rheum Dis 2015;18:587-90.

11 Keynan Y, Rimar D. Reactive arthritis--the appropriate name. Isr Med Assoc J 2008;10:256-8.

12 Bauer W, Engleman EP. A syndrome of unkown etiology characterized by urethritis, conjunctivitis, and arthritis [so-called Reiter's disease]. Trans Assoc Am Physcicians 1942;57:307-13.

13 Paronen I. Reiter's disease; study of 344 cases observed in Finland. Acta Med 1948.

14 Noer HR. An "experimental" epidemic of Reiter's syndrome. JAMA 1966;198:693-8.

15 Calin A, Fries JF. An "experimental" epidemic of Reiter's syndrome revisited. Follow-up evidence on genetic and environmental factors. Ann Intern Med 1976;84:564-6.

16 Ahvonen P, Sievers K, Aho K. Arthritis associated with Yersinia enterocolitica infection. Acta Rheumatol Scand 1969;15:232-53.

17 Rose HM, Ragan C. Differential agglutination of normal and sensitized sheep erythrocytes by sera of patients with rheumatoid arthritis. Proc Soc Exp Biol Med 1948;68:1-6.

18 Waaler E. On the occurrence of a factor in human serum activating the specific agglutination of sheep blood corpuscles 1939;17:172-88.

19 Franklin EC, Holman HR, Muller-Eberhard HJ, et al. An unusual protein component of high molecular weight in the serum of certain patients with rheumatoid arthritis. J Exp Med 1957;105:425-38.

20 Zvaifler NJ. The arthritis of chronic ulcerative colitis. In: Lukash WM, Raymond BJ, eds. The systemic manifestation of inflammatory bowel disease. Springfield, 1975: 230-8.

21 Fernandez-Herlihy L. The articular manifestations of chronic ulcerative colitis. New England Journal of Medicine 1959;261:259-63.

22 Wright V, Watkinson G. The arthritis of ulcerative colitis. Medicine 1959;38:243-62.

23 Steinberg VL, Storey G. Ankylosing spondylitis and chronic inflammatory lesions of the intestines. Br Med J 1957;2:1157-9.

24 Zvaifler NJ, Martel W. Spondylitis in chronic ulcerative colitis. Arthritis Rheum 1960;3:76-87.

25 Wright V, Watkinson G. Sacro-Iliitis and ulcerative colitis. Br Med J 1965;2:675-80.

26 Rotstein J, Entel I, Zeviner B. Arthritis associated with ulcerative colitis. Ann Rheum Dis 1963;22:194-7.

27 Acheson ED. An association between ulcerative colitis, regiona enteritis, and ankylosing spondylitis. Q J Med 1960;29:489-99.

28 Clark RL, Muhletaler CA, Margulies SI. Colitic arthritis. Clinical and radiographic manifestations. Radiology 1971;101:585-94. 
29 McEwen C, Lingg C, Kirsner JB, et al. Arthritis accompanying ulcerative colitis. Am J Med 1962;33:923-41.

30 Moll JM, Haslock I, Macrae IF, et al. Associations between ankylosing spondylitis, psoriatic arthritis, Reiter's disease, the intestinal arthropathies, and Behcet's syndrome. Medicine 1974;53:343-64.

31 Schlosstein L, Terasaki PI, Bluestone R, et al. High association of an HL-A antigen, W27, with ankylosing spondylitis. N Engl J Med 1973;288:704-6.

32 Brewerton DA, Caffrey M, Nicholls A, et al. HI-A 27 and arthropathies associated with ulcerative colitis and psoriasis. Lancet 1974;1:956-8.

33 Fletcher E. Medical disorders of the locomotor system including the rheumatic diseases. Baltimore: The Williams AND Wilkins company, 1951: 123-5.

34 Batson OV. The function of the vertebral veins and their role in the spread of metastases. Ann Surg 1940;112:138-49.

35 Breban $\mathrm{M}$, Beaufrère $\mathrm{M}$, Glatigny $\mathrm{S}$. The microbiome in spondyloarthritis. Best Pract Res Clin Rheumatol 2019;33:101495.

36 Hammer RE, Maika SD, Richardson JA, et al. Spontaneous inflammatory disease in transgenic rats expressing HLA-B27 and human beta 2M: an animal model of HLA-B27-associated human disorders. Cell 1990;63:1099-112.

37 Taurog JD, Richardson JA, Croft JT, et al. The germfree state prevents development of gut and joint inflammatory disease in HLA-B27 transgenic rats. J Exp Med 1994;180:2359-64.

38 Asquith M, Davin S, Stauffer P, et al. Intestinal metabolites are profoundly altered in the context of HLA-B27 expression and functionally modulate disease in a rat model of spondyloarthritis. Arthritis Rheumatol 2017;69:1984-95.

39 Lin P, Bach M, Asquith M, et al. Hla-B27 and human beta2microglobulin affect the gut microbiota of transgenic rats. PLoS One 2014:9:e105684.

40 Asquith M, Sternes PR, Costello M-E, et al. Hla alleles associated with risk of ankylosing spondylitis and rheumatoid arthritis influence the gut microbiome. Arthritis Rheumatol 2019;71:1642-50.

41 Gill T, Brooks SR, Rosenbaum JT, et al. Novel Inter-omic analysis reveals relationships between diverse gut microbiota and host immune dysregulation in HLA-B27-Induced experimental spondyloarthritis. Arthritis Rheumatol 2019;71:1849-57.

42 Gill T, Asquith M, Brooks SR, et al. Effects of HLA-B27 on gut microbiota in experimental spondyloarthritis implicate an ecological model of dysbiosis. Arthritis Rheumatol 2018;70:555-65.

43 Benham H, Rehaume LM, Hasnain SZ, et al. Interleukin-23 mediates the intestinal response to microbial $\beta-1,3$-glucan and the development of spondyloarthritis pathology in SKG mice. Arthritis Rheumatol 2014;66:1755-67.

44 Rehaume LM, Mondot S, Aguirre de Cárcer D, et al. ZAP-70 genotype disrupts the relationship between microbiota and host, leading to spondyloarthritis and ileitis in SKG mice. Arthritis Rheumatol 2014;66:2780-92.

45 Schaubeck M, Clavel T, Calasan J, et al. Dysbiotic gut microbiota causes transmissible Crohn's disease-like ileitis independent of failure in antimicrobial defence. Gut 2016:65:225-37.

46 Norman ELA, Kuhn K. Gut-Joint T cell trafficking in a model of Bacteria-Driven murine IBD-Spa. 2018 ACR/ARHP annual meeting 2018.

47 Chriswell ME, Kuhn KA. Microbiota-mediated mucosal inflammation in arthritis. Best Pract Res Clin Rheumatol 2019;33:101492.

48 Ivanov II, Atarashi K, Manel N, et al. Induction of intestinal Th17 cells by segmented filamentous bacteria. Cell 2009;139:485-98.

49 Atarashi K, Tanoue T, Ando M, et al. Th17 cell induction by adhesion of microbes to intestinal epithelial cells. Cell 2015;163:367-80.

50 Niess JH, Leithäuser F, Adler G, et al. Commensal gut flora drives the expansion of proinflammatory CD4 T cells in the colonic lamina propria under normal and inflammatory conditions. $J$ Immunol 2008:180:559-68

51 Zizzo G, De Santis M, Bosello SL, et al. Synovial fluid-derived T helper 17 cells correlate with inflammatory activity in arthritis, irrespectively of diagnosis. Clin Immunol 2011;138:107-16.

52 Fragoulis GE, Liava C, Daoussis D, et al. Inflammatory bowel diseases and spondyloarthropathies: from pathogenesis to treatment. World J Gastroenterol 2019;25:2162-76.

53 Weaver CT, Hatton RD, Mangan PR, et al. II-17 family cytokines and the expanding diversity of effector T cell lineages. Annu Rev Immunol 2007;25:821-52.

54 McGonagle DG, Mclnnes IB, Kirkham BW, et al. The role of IL-17A in axial spondyloarthritis and psoriatic arthritis: recent advances and controversies. Ann Rheum Dis 2019;78:1167-78.

55 Berlinberg A, Kuhn KA. Barrier lymphocytes in spondyloarthritis. Curr Opin Rheumatol 2020;32:343-8.
56 Venken K, Elewaut D. New immune cells in spondyloarthritis: key players or innocent bystanders? Best Pract Res Clin Rheumatol 2015;29:706-14.

57 Sherlock JP, Joyce-Shaikh B, Turner SP, et al. II-23 induces spondyloarthropathy by acting on ROR- $\gamma \mathrm{t}+\mathrm{CD} 3+\mathrm{CD} 4-\mathrm{CD} 8$ entheseal resident T cells. Nat Med 2012;18:1069-76.

58 Venken $\mathrm{K}$, Jacques $\mathrm{P}$, Mortier $\mathrm{C}$, et al. Roryt inhibition selectively targets IL-17 producing iNKT and $\gamma \delta-T$ cells enriched in spondyloarthritis patients. Nat Commun 2019;10:9.

59 Ciccia F, Guggino G, Rizzo A, et al. Type 3 innate lymphoid cells producing IL-17 and IL-22 are expanded in the gut, in the peripheral blood, synovial fluid and bone marrow of patients with ankylosing spondylitis. Ann Rheum Dis 2015;74:1739-47.

60 Haga K, Chiba A, Shibuya T, et al. MAIT cells are activated and accumulated in the inflamed mucosa of ulcerative colitis. $J$ Gastroenterol Hepatol 2016;31:965-72.

61 Noto Llana M, Sarnacki SH, Vázquez MV, et al. Salmonella enterica induces joint inflammation and expression of interleukin-17 in draining lymph nodes early after onset of enterocolitis in mice. Infect Immun 2012;80:2231-9.

62 Godinez I, Raffatellu M, Chu H, et al. Interleukin-23 orchestrates mucosal responses to Salmonella enterica serotype typhimurium in the intestine. Infect Immun 2009;77:387-98.

63 Noto Llana M, Sarnacki SH, Morales AL, et al. Activation of INKT cells prevents Salmonella-Enterocolitis and Salmonella-induced reactive arthritis by downregulating IL-17-producing $\gamma \delta \mathrm{T}$ cells. Front Cell Infect Microbiol 2017;7:398.

64 Reveille JD. HLA-B27 and the seronegative spondyloarthropathies. Am J Med Sci 1998;316:239-49.

65 Steer S, Jones $\mathrm{H}$, Hibbert J, et al. Low back pain, sacroiliitis, and the relationship with HLA-B27 in Crohn's disease. J Rheumatol 2003;30:518-22.

66 Palm O, Moum B, Ongre A, et al. Prevalence of ankylosing spondylitis and other spondyloarthropathies among patients with inflammatory bowel disease: a population study (the IBSEN study). $J$ Rheumatol 2002;29:511-5.

67 Colbert RA, DeLay ML, Klenk El, et al. From HLA-B27 to spondyloarthritis: a journey through the ER. Immunol Rev 2010:233:181-202.

68 DeLay ML, Turner MJ, Klenk El, et al. HLA-B27 misfolding and the unfolded protein response augment interleukin-23 production and are associated with Th17 activation in transgenic rats. Arthritis Rheum 2009;60:2633-43.

69 Ramos M, Alvarez I, Sesma L, et al. Molecular mimicry of an HLAB27-derived ligand of arthritis-linked subtypes with chlamydial proteins. J Biol Chem 2002;277:37573-81.

70 Peluso R, Di Minno MND, lervolino S, et al. Enteropathic spondyloarthritis: from diagnosis to treatment. Clin Dev Immunol 2013;2013:1-12.

71 Duerr RH, Taylor KD, Brant SR, et al. A genome-wide association study identifies IL23R as an inflammatory bowel disease gene. Science 2006;314:1461-3.

72 Rahman P, Inman RD, Gladman DD, et al. Association of interleukin-23 receptor variants with ankylosing spondylitis. Arthritis Rheum 2008;58:1020-5.

73 Leirisalo-Repo M, Turunen U, Stenman S, et al. High frequency of silent inflammatory bowel disease in spondylarthropathy. Arthritis Rheum 1994;37:23-31.

74 Dumas E, Venken K, Rosenbaum JT, et al. Intestinal microbiota, HLA-B27, and spondyloarthritis: dangerous liaisons. Rheum Dis Clin North Am 2020;46:213-24.

75 Tajik N, Frech M, Schulz O, et al. Targeting zonulin and intestinal epithelial barrier function to prevent onset of arthritis. Nat Commun 2020;11:11

76 Salmi M, Andrew DP, Butcher EC, et al. Dual binding capacity of mucosal immunoblasts to mucosal and synovial endothelium in humans: dissection of the molecular mechanisms. J Exp Med 1995:181:137-49.

77 Salmi M, Jalkanen S. Human leukocyte subpopulations from inflamed gut bind to joint vasculature using distinct sets of adhesion molecules. J Immunol 2001;166:4650-7.

78 Johansson-Lindbom B, Svensson M, Wurbel M-A, et al. Selective generation of gut tropic $T$ cells in gut-associated lymphoid tissue (GALT): requirement for GALT dendritic cells and adjuvant. $J$ Exp Med 2003;198:963-9.

79 Berlin C, Berg EL, Briskin MJ, et al. Alpha 4 beta 7 integrin mediates lymphocyte binding to the mucosal vascular addressin MAdCAM-1. Cell 1993;74:185-95.

80 Stenstad H, Ericsson A, Johansson-Lindbom B, et al. Gut-Associated lymphoid tissue-primed CD4+ T cells display CCR9-dependent and -independent homing to the small intestine. Blood 2006;107:3447-54. 
81 Hermann E, Fleischer B, Mayet WJ, et al. Response of synovial fluid $\mathrm{T}$ cell clones to Yersinia enterocolitica antigens in patients with reactive Yersinia arthritis. Clin Exp Immunol 1989;75:365-70.

82 Baeten D, Demetter P, Cuvelier CA, et al. Macrophages expressing the scavenger receptor CD163: a link between immune alterations of the gut and synovial inflammation in spondyloarthropathy. J Pathol 2002;196:343-50.

83 Demetter P, De Vos M, Van Huysse JA, et al. Colon mucosa of patients both with spondyloarthritis and Crohn's disease is enriched with macrophages expressing the scavenger receptor CD163. Ann Rheum Dis 2005;64:321-4.

84 Kontoyiannis D, Pasparakis M, Pizarro TT, et al. Impaired on/ off regulation of TNF biosynthesis in mice lacking TNF AUrich elements: implications for joint and gut-associated immunopathologies. Immunity 1999;10:387-98.

85 Ellinghaus D, Jostins L, Spain SL, et al. Analysis of five chronic inflammatory diseases identifies 27 new associations and highlights disease-specific patterns at shared loci. Nat Genet 2016;48:510-8.

86 Robinson PC, Leo PJ, Pointon JJ, et al. Exome-wide study of ankylosing spondylitis demonstrates additional shared genetic background with inflammatory bowel disease. NPJ Genom Med 2016;1:16008.

87 Stoll ML, Kumar R, Lefkowitz EJ, et al. Fecal metabolomics in pediatric spondyloarthritis implicate decreased metabolic diversity and altered tryptophan metabolism as pathogenic factors. Genes Immun 2016:17:400-5.
88 Berlinberg AJ, Regner EH, Stahly A, et al. Multi 'Omics Analysis of Intestinal Tissue in Ankylosing Spondylitis Identifies Alterations in the Tryptophan Metabolism Pathway. Front Immunol 2021;12:587119.

89 Qaiyum Z, Gracey E, Yao Y, et al. Integrin and transcriptomic profiles identify a distinctive synovial CD8+ T cell subpopulation in spondyloarthritis. Ann Rheum Dis 2019;78:1566-75.

90 Lefferts A, Regner E, Stahly A. Circulating Mature Granzyme B+ T Cells Distinguish Crohn's Disease Associated Axial Spondyloarthritis from Axial Spondyloarthritis and Crohn's Disease. Research Square 138435/v1 2020

91 Berlinberg A, Kuhn KA. Molecular biology approaches to understanding spondyloarthritis. Rheum Dis Clin North Am 2020;46:203-11.

92 Bein A, Shin W, Jalili-Firoozinezhad S, et al. Microfluidic Organ-ona-Chip models of human intestine. Cell Mol Gastroenterol Hepatol 2018;5:659-68.

93 Angus HCK, Butt AG, Schultz M, et al. Intestinal organoids as a tool for inflammatory bowel disease research. Front Med 2019;6:334.

94 Poletti M, Arnauts K, Ferrante M, et al. Organoid-based models to study the role of host-microbiota interactions in IBD. J Crohns Colitis 2020:jjaa257.

95 Beaurivage C, Kanapeckaite A, Loomans C, et al. Development of a human primary gut-on-a-chip to model inflammatory processes. Sci Rep 2020;10:21475. 